\title{
Legislative approaches to tackling the obesity epidemic
}

\author{
Mark J. Eisenberg MD MPH, Renée Atallah MSc, Sonia M. Grandi MSc, Sarah B. Windle MPH, Elliot M. Berry MD
}

Competing interests: Elliot Berry has received fees for expert testimony on nutritional issues from the food industry, speaker fees from Boehringer Ingelheim for lectures at conferences on nutrition and weight management, and research grants from the Israel Academy of Sciences and Humanities for basic research on the influence of nutrition on cognitive function. Patents on endocannabinoids and leptin are held jointly by him and other research workers and the Hebrew University. No competing interests declared by the other authors.

This article has been peer reviewed.

Correspondence to: Dr. Mark J. Eisenberg, mark.eisenberg@mcgill.ca

CMAJ 2011. DOI:10.1503 /cmaj.101522

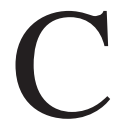
anada and other developed countries are facing an obesity epidemic, with a substantial rise in the prevalence of overweight and obesity among adults and children. ${ }^{1-3}$ The 2007-2009 Canadian Health Measures Survey revealed that $37 \%$ of adults were overweight (body mass index [BMI] 25.0-29.9) and $24 \%$ were obese (BMI > 30)..$^{1,2}$ Over the last three decades, Canadians have become heavier and less fit. Also worrisome is that Canadians aged 20-39 years have the BMIs that people aged 40 or older had three decades ago. If these trends continue over the next 25 years, half of Canadians over the age of 40 will be obese.'

Obesity is expected to surpass smoking as the leading cause of preventable morbidity and mortality. ${ }^{4}$ Obesity reduces life expectancy by more than 10 years as a comorbidity with coronary artery disease, osteoarthritis, dyslipidemia, hypertension, stroke and type 2 diabetes. ${ }^{46}$ Thus, obesity causes considerable morbidity and mortality and represents a burden of $\$ 3.96$ billion on the Canadian economy each year. ${ }^{7}$

Of additional concern is the unprecedented rise in childhood obesity, which increases the risk of adult obesity and its complications. ${ }^{6}$ In the 2007-2009 Canadian Health Measures Survey, more than $25 \%$ of children and teenagers were overweight (17\%) or obese (9\%). Since 1981, the prevalence of overweight and obesity among teenagers $15-19$ years old has approximately doubled, from $14 \%$ to $31 \%$ among boys and from $14 \%$ to $25 \%$ among girls. ${ }^{2}$

Public pressure to combat obesity has resulted in several legislative interventions in several developed countries. However, whether these initiatives are feasible and effective is questionable. In this article, we provide an overview of legisla-

\section{- KeY POINTS}

- Canada is facing an obesity epidemic, with a substantial and rising prevalence of overweight and obese adults and children.

- The steep rise in obesity over the past few decades is due to responses to an obesogenic environment.

- There is increasing awareness of the role that governments, corporations and educators can play in preventing and reducing obesity.

- Legislative approaches, together with environmental modifications, can be an effective means of reversing the growing problem of obesity in Canada. tive approaches that could be implemented in Canada. We first look at why a public health approach is necessary.

\section{The need to integrate a public health approach}

Obesity has traditionally been considered a medical "problem" for physicians to treat. ${ }^{8}$ According to the 2006 Canadian clinical practice guidelines on the management and prevention of obesity in adults and children, the monitoring of weight in patients at risk for obesity should be an integral part of primary care. ${ }^{6}$ However, minimal attention is often given to long-term weight management by primary care physicians. ${ }^{9.10}$

Interventions that have been used to promote weight loss include behavioural counselling, dieting, exercise, pharmacotherapy and surgical interventions. The efficacy of these interventions (with the exception of surgery) to provide sustainable results remains questionable. ${ }^{6,11}$ These interventions also fail to recognize the obesogenic environment, which includes widespread availability of energy-dense, high-fat foods, decreased opportunities for physical activity (e.g., labour-saving devices) and increased sedentary behaviour. ${ }^{6,12}$ Given the recent rise in the prevalence of obesity, it is unlikely that the obesity epidemic is due to metabolic or genetic changes; therefore, it must be due to normal responses to the obesogenic environment. Because individuals may have great difficulty making lifestyle modifications, and in the absence of effective medication or widespread surgical interventions, a paradigm shift in how obesity is managed is needed that takes into account such an environment. ${ }^{6,8,13}$

An example is the Sodium Reduction Strategy for Canada, a set of 27 recommendations developed because of the growing cardiovascular health and economic burden linked to excessive sodium consumption..$^{14}$ The implementation of these recommendations involves the cooperation of multiple stakeholders, provincial and federal governments, nongovernmental organizations, health professionals, the food industry and consumer groups to reduce the amount of sodium in foods, educate the public, conduct research, and set up a system to 
evaluate and monitor the progress of the strategy. ${ }^{14}$

If we are to combat obesity, a public health approach is needed that includes legislative interventions. ${ }^{6,13}$ In contrast to the medical model, this places responsibility at the societal and population levels and focuses on modifiable environmental contributors to obesity. ${ }^{8}$ Such an approach has been used successfully to reduce the prevalence of cigarette smoking in Canada and elsewhere, with tobacco taxes, antismoking campaigns and advertising bans. ${ }^{8}, 13$ Several provinces are considering implementing similar legislative measures to reduce the prevalence of obesity despite the scarcity of evidence. British Columbia's proposed Public Health Act will allow the government to introduce regulations such as banning the use of trans fatty acids (trans fats), food advertisements targeting children and access to vending machines by children. ${ }^{15}$

Legislative interventions that help Canadians make healthier choices are fundamental in curbing the obesity epidemic. This, however, can be achieved only if key stakeholders are involved at all levels of the decision-making process. The potential negative effect of legislative measures not involving key stakeholders can be seen by the increase in the prevalence of type 2 diabetes among adolescents in Ontario shortly following the removal of physical activity programs from schools in the 1990s. ${ }^{16}$

Legislative approaches could be implemented in Canada at three levels - government, corporate and school/youth.

\section{Government-level interventions}

\section{Taxing junk food}

A proposed intervention for reducing the consumption of energy-dense and high-fat drinks and foods is to implement a "sin" or "junk food" tax. ${ }^{6}$ It has been highly debated in the Canadian media, notably in Ontario and Quebec. The rationale stems from the success of cigarette taxes, a proven and effective intervention to combat smoking. ${ }^{17}$ However, it remains unclear whether a junk food tax is feasible or appropriate. ${ }^{13}$ Proponents of a dedicated junk food tax suggest that the large revenues generated could be used to subsidize healthy food prices or to fund obesity prevention programs. ${ }^{6.13}$

Opponents of the tax have identified several potential barriers, including the relative inelasticity of fast-food consumption (i.e., a cost increase may not create a substantial reduction in consumption); a potential shift in demand to other nontaxed energy-dense foods; and the difficulty in defining which foods should be taxed. ${ }^{10}$ Although every cigarette is bad, all foods, even junk food, have some nutritional value. Taxation could also have a disproportionately negative effect on lower socioeconomic classes, which are typically more dependent on fast foods for their nutrition. ${ }^{12,18}$ Lastly, public opposition to such taxes may be substantial. For instance, in November 2009 the Ontario government decided not to apply its new Harmonized Sales Tax to the cost of fast foods and coffee, for fear of taxpayers' resentment and resulting negative political impact. ${ }^{19}$

\section{Improving nutritional labelling and definitions of serving sizes}

Another potential government-level legislative intervention is to improve nutritional labelling of products, including items on restaurant menus. ${ }^{6}$ These labels can provide written or graphic warnings, similar to those on cigarette packaging. An example is the "traffic-light system" used in the United Kingdom since 2005. This voluntary labelling system uses red, green and amber colour coding to indicate the nutritional value of food ingredients based on the daily recommended intakes for fats, saturated fats, sugar and sodium; in some instances, calorie content is considered. These labels now accompany the majority of processed foods in the United Kingdom and have been found to reduce confusion and help consumers make healthier choices, and have caused manufacturers to reformulate products to improve their nutritional quality. ${ }^{20}$ However, it is unclear whether such labels in Canada would actually modify consumer habits without an accompanying educational program. ${ }^{21}$

Health Canada launched the multimedia "\% daily value" educational campaign in 2010 to help consumers understand nutritional labels. Aside from educational campaigns, serving sizes need to be more clearly defined. Current regulations allow manufacturers, food chains and restaurants to determine serving sizes and describe nutritional information based on them. ${ }^{22}$ Not only does this render comparisons more difficult (e.g., for similar products from different brands), these servings are often unrepresentative of "real-world" portions. Health Canada is planning a number of revisions to the current labelling regulations, with the "\% daily value" program being the first step in that direction.

\section{Banning certain obesogenic foods and ingredients}

Bans on obesogenic foods and ingredients, especially trans fats, represent another governmentlevel legislative intervention proposed to curb the obesity epidemic. In 2003, Denmark was the first to implement limits on trans fats in processed foods; New York City followed in 2007. ${ }^{13}$ Formal evaluations of these interventions are pending. In Canada, the city of Calgary has 
banned the use of trans fats in its restaurants, ${ }^{21}$ and Health Canada implemented the Trans Fat Monitoring Program in 2007 as one of the Task Force on Trans Fat's recommendations..$^{23}$

The rationale for this intervention is that trans fats contribute to the obesity epidemic in two ways. First, there is evidence that they may promote weight gain. ${ }^{24}$ Second, trans fats in foods (mostly fried and baked) prolong their shelf-life, making these products cheaper and more readily available, thus increasing their consumption. ${ }^{25}$

Opponents to this type of intervention point out that the scientific evidence for banning the use of trans fats is insufficient, because it fails to show that they are more harmful than saturated fats. In addition, there is a potential market shift toward consumption of saturated fats in place of trans fats. ${ }^{13}$ Finally, there is some concern that the substitution of trans fats with other fats will have no effect on the energy content of these foods and therefore will not significantly reduce the prevalence of obesity. ${ }^{25}$

\section{Regulating sodium consumption}

Health Canada's 2007 Community Health Survey ${ }^{26}$ showed that, on average, sodium intake was about $150 \%$ the recommended maximum daily intake of $2300 \mathrm{mg}$. Because high sodium intake contributes to the development of hypertension, this represents a growing cardiovascular health risk and economic burden (estimated at $\geq \$ 2.99$ billion yearly both in direct and indirect costs). ${ }^{14}$

As with trans fats, sodium is an ingredient often present in excess in junk and processed foods that may also directly contribute to the obesity epidemic by enhancing the palatability and overconsumption of these foods. Thus, it has been proposed that reducing the amount of sodium in processed and junk foods, thereby making them less palatable, may help reduce the obesity epidemic. . $^{1427}$

Moreover, sodium regulation is an example of the epidemiologic "prevention paradox," whereby "a measure that brings large benefits to the community offers little to each participating individual." ${ }^{28}$ Thus, lowering the daily sodium consumption of Canadians may not represent large health gains for each individual, but it will benefit the country's population as a whole. Opponents of this strategy say that it is not useful, since the benefits gained by each individual are too small and not easily measureable. ${ }^{28}$

\section{Modifying the built environment}

Over the past number of decades, the increasing use of transportation has led to a more sedentary lifestyle for most Canadians. Land development has resulted in differential usage (i.e., residential areas separated from commercial areas), making vehicular travel more practical than active trans- portation such as walking and bicycling..$^{29}$ Studies have suggested that people living in neighbourhoods with opportunities for safe physical activity (e.g., sidewalks, bicycle paths, public facilities, recreational facilities, streetlights, access to trails) are more active and have lower rates of obesity than people living in neighbourhoods without these opportunities. ${ }^{18}$

Another environmental factor linked to obesity includes socioeconomic status, whose complex and inverse association with obesity has been illustrated in several studies. ${ }^{6} 18$ Two key factors involved include access to healthy food versus fast-food outlets and neighbourhood safety. Evidence shows that, compared with people living in areas of higher socioeconomic status, residents in lower socioeconomic neighbourhoods are disadvantaged regarding access to fresh and healthy foods such as fruits and vegetables. With limited access to supermarkets, they rely more on convenience stores and fastfood restaurants. ${ }^{18}$ In addition, neighbourhood safety affects residents' physical activity levels, since crime and violence rates can deter individuals from walking. ${ }^{18}$

Although the studies outlining the association between neighbourhood characteristics and obesity were cross-sectional, the possibility cannot be ruled out that healthier individuals choose to live in "healthier built" neighbourhoods. A true causal association with regards to neighbourhood-associated risk factors and obesity has yet to be clearly established. ${ }^{18}$

Finally, because people of lower socioeconomic status are often marginalized and have fewer resources, new, innovative solutions may be learned from the "positive deviance" approach. This approach is based on the "observation that in most settings, a few at-risk individuals follow uncommon, beneficial practices and consequently experience better outcomes than their neighbours who share similar risks (and the same environment). ${ }^{30}$ Positive deviance can lead to public health solutions that are generally cost-effective and well-adapted to the communities in which they were developed. ${ }^{30}$ The incorporation of these solutions into public health measures for residents in lower socioeconomic neighbourhoods might achieve more successful results.

\section{Restaurant-based interventions}

Closely linked to the modification of the built environment, zoning bylaws could be implemented that regulate the number and density of fast-food restaurants and their distance from schools and hospitals, or that ban them outright from specified areas and neighbourhoods. ${ }^{31}$ A number of cities in the United States, among them Detroit, Michigan and Berkeley, California, have adopted such bylaws. ${ }^{31}$ These 
interventions could have a substantial impact on the prevalence of obesity. A study in the United States showed that one-third of public secondary schools have one or more fast-food restaurants or convenience stores within walking distance of them, with higher numbers near schools in the lowest socioeconomic neighbourhoods. ${ }^{32}$

The proportion of food consumed outside the home has increased dramatically in North America over the past few decades..$^{33}$ It has therefore become increasingly important to detail the nutritional value of foods consumed in restaurants. In 2009, the Ontario Medical Association requested legislative measures to force restaurant chains to display calorie counts on menus as a means of increasing awareness and influencing consumer choices. ${ }^{34}$ Menu labelling could also pressure companies to modify their products to provide healthier alternatives, as was seen with the United Kingdom's traffic-light system. Opponents of this intervention believe that including nutritional information will have minimal impact on the dietary habits of the public without an accompanying education program..$^{33}$ Evidence is needed to support the effectiveness and feasibility of implementing such interventions.

\section{Corporate-level interventions}

The workplace constitutes another potential arena for obesity prevention and reduction. Companies should encourage healthy behaviours, such as eating well and exercising, because of the financial benefits of having healthy employees (e.g., decreased absenteeism and spending on health care). ${ }^{6}$

Companies can be encouraged, as a way for them to fulfill their corporate social responsibilities, to set aside a percentage of their profits for anti-obesity campaigns or interventions targeted at increasing physical activity. ${ }^{6}$ Furthermore, the 2006 guidelines on the management and prevention of obesity suggest removing sales taxes on fitness equipment and offering tax incentives to employers who provide their employees with fitness facilities. ${ }^{6}$ However, it remains unclear whether or not corporate incentives are a viable policy option to fight the obesity epidemic. ${ }^{6}$

\section{School- and youth-level interventions}

\section{Banning advertisements for unhealthy foods}

An early antitobacco strategy used by the government was to outlaw cigarette advertisements in the media, on billboards and at sporting events. Based on the success of these interventions, the 2006 obesity guidelines recommend limiting the "screen time" of children (i.e., television, video and computer games) to reduce their exposure to food advertisements. ${ }^{6}$ Quebec has imposed restrictions on advertisements during children's programs. ${ }^{12}$ It has been well-demonstrated that advertisements on television and in schools can have a negative impact on children's consumption habits, ${ }^{35}$ however, the link between poor health outcomes and advertising of unhealthy foods is still unclear. ${ }^{33}$

\section{Banning the sale of junk food in schools}

The sale of junk food and soft drinks in school cafeterias and vending machines can have a negative effect on the nutrition of growing children and the rising rates of obesity. The percentage of daily energy obtained from soft drinks has increased markedly over the past decades, and the energy intake from sugar-sweetened beverages has been linked to the increase in obesity. ${ }^{36}$ In many schools, vending machines are readily available and offer only a limited choice of healthy foods.

Several measures have already been implemented in Canada to limit access to junk food in schools. The Ontario provincial government has mandated the replacement of food and beverages in vending machines with healthy and nutritious alternatives that meet criteria specified by Dietitians of Canada with respect to fat, fibre, sodium, calcium, and vitamin and mineral contents. ${ }^{37}$ The New Brunswick provincial government banned junk food from vending machines in elementary schools in 2005. Some districts have also banned the sale of sugary and unhealthy foods from their schools and vending machines, or banned vending machines altogether. ${ }^{13,33}$

Opponents note that replacing unhealthy snack foods such as chips and soda with isocaloric juice and nut equivalents would not have the intended effect on obesity rates. Proponents counter that, although the energy value may be identical, the nutritional content differs, favouring a "healthier" alternative. Ideally, there would be a shift toward items with decreased fat and sugar content, such as trail mix, apple slices and granola bars. Intervening to effect lifestyle modifications and promote healthy eating habits in children and ado lescents is key, as these are most likely to have positive long-lasting health benefits. ${ }^{6.12}$

\section{The evidence-to-practice gap}

A wide gap exists between initiatives implemented internationally to curb the obesity epidemic and the actual number implemented or evaluated in the Canadian context. ${ }^{21,36}$ Discussions regarding viable options have been ongoing for some time, but their implementation has been delayed by political and 
legislative constraints. The 2006 obesity guidelines provided a brief but limited overview of legislative interventions. ${ }^{6}$ In addition, they note that "research is needed to determine the most effective interventions to deliver, appropriate delivery vehicles and the circumstances required for success." $\%$

\section{Conclusion}

Although obesity has traditionally been conceptualized as a physical problem for physicians to treat, ${ }^{8}$ there is increasing awareness of the role that governments, corporations and educators can play in preventing and reducing obesity. A number of legislative initiatives have already been implemented in Canada, but they require monitoring and assessment. Community-based interventions have failed in the past because they were inadequately supported by legislative measures that provided an impact at the societal level.

The growing problem of obesity in Canada can be reversed only with an integrated approach involving both the public health and medical models. Stakeholders at all levels must be involved to achieve the greatest overall impact. There is a greater need than ever for strong political will to effect these complex societal changes, and for champions at all levels of government to step forward and do so in new, innovative and effective ways.

\section{References}

1. Shields M, Tremblay MS, Laviolette M, et al. Fitness of Canadian adults: results from the 2007-2009 Canadian Health Measure Survey. Health Rep 2010;21(1).

2. Tremblay MS, Shields M, Laviolette M, et al. Fitness of Canadian children and youth: results from the 2007-2009 Canadian Health Measures Survey. Health Rep 2010;21.

3. World Health Organization. The world health report 2002. reducing risks, promoting healthy life. Geneva (Switzerland): The Organization; 2002. Available: www.who.int/whr/2002/en /whr02_en.pdf (accessed 2010 Oct. 7).

4. Tjepkema M. Adult obesity. Health Rep 2007;17:9-25.

5. Fontaine KR, Redden DT, Wang C, et al. Years of life lost due to obesity. JAMA 2003;289:187-93.

6. 2006 Canadian clinical practice guidelines on the management and prevention of obesity in adults and children. CMAJ 2007; 176(8 Suppl):1-117.

7. Anis AH, Zhang W, Bansback N, et al. Obesity and overweight in Canada: an updated cost-of-illness study. Obes Rev 2010;11:31-40.

8. Wang SS, Brownell KD. Public policy and obesity: the need to marry science with advocacy. Psychiatr Clin North Am 2005;28: 235-52.

9. O'Brien SH, Holubkov R, Reis EC. Identification, evaluation, and management of obesity in an academic primary care center. Pediatrics 2004;114:e154-9.

10. Forman-Hoffman V, Little A, Wahls T. Barriers to obesity management: a pilot study of primary care clinicians. BMC Fam Pract 2006;7:35.

11. Dubnov-Raz G, Berry EM. Dietary approaches to obesity. Mt Sinai J Med 2010;77:488-98.

12. Understanding the forces that influence our eating habits. Can J Public Health 2005;96(Suppl):S1-46.

13. Gostin LO. Law as a tool to facilitate healthier lifestyles and prevent obesity. JAMA 2007;297:87-90.

14. Sodium Reduction Strategy for Canada - recommendations of the Sodium Working Group. Ottawa (ON): Health Canada; 2010. Available: www.hc-sc.gc.ca/fn-an/nutrition/sodium /strateg/index-eng.php (accessed 2011 Apr. 13).
15. Public Health Act. Victoria (BC): British Columbia Ministry of Health Services. Available: www.health.gov.bc.ca/phact/overview .html\#3.3 (accessed 2011 Feb. 18).

16. Lipscombe LL, Hux JE. Trends in diabetes prevalence, incidence, and mortality in Ontario, Canada 1995-2005: a population-based study. Lancet 2007;369:750-6.

17. Kaiserman MJ, Rogers B. Forty year trends in Canadian tobacco sales. Can J Public Health 1992;83:404-6.

18. Black JL, Macinko J. Neighborhoods and obesity. Nutr Rev 2008; $66: 2-20$

19. Poll: $90 \%$ in B.C. and Ontario say HST is a government tax grab. Vancouverite 2009 Dec. 5. Available: www.vancouverite.com /2009/12/05/poll-90-in-b-c-and-ontario-say-hst-is-a-government-tax -grab/ (accessed 2011 Apr. 11).

20. A year at the Food Standards Agency 2008/09. London (UK): Food Standards Agency; 2009. Available: www.food.gov.uk/multimedia /pdfs/publication/annualreport0709.pdf (accessed 2011 Apr. 19).

21. Kondro W. Canada needs paradigm shift in public health nutrition. CMAJ 2008;179:1259-61.

22. Canadian Food Inspection Agency. Guide to food labelling and advertising. Ottawa (ON): the Agency; 2010. Available: www .inspection.gc.ca/english/fssa/labeti/labetie.shtml (accessed 2010 Feb. 3)

23. Trans Fat Monitoring Program. Ottawa (ON): Health Canada; 2009. Available: www.hc-sc.gc.ca/fn-an/nutrition/gras-trans-fats /tfa-age tc-tm-eng.php (accessed 2010 Feb. 26).

24. Thompson AK, Minihane AM, Williams CM. Trans fatty acids and weight gain. Int J Obes (Lond) 2011;35(3):315-24.

25. Nutrition Evaluation Division. TRANSforming the food supply. A report of the Trans Fat Task Force to the Minister of Health. 2006. Ottawa (ON): Health Canada; 2006. Available: www.hcsc.gc.ca/fn-an/alt_formats/hpfb-dgpsa/pdf/nutrition/tf-gt_rep-rap -eng.pdf (accessed 2011 Jan. 11)

26. Nutrient intakes from food: provincial, regional, and national summary tables. In: Canadian Community Health Survey, cycle 2.2, nutrition (2004). Vol 1. Ottawa (ON): Health Canada; 2007.

27. Yeomans MR, Blundell JE, Leshem M. Palatability: response to nutritional need or need-free stimulation of appetite? Br J Nutr 2004;92(Suppl 1):S3-14.

28. Rose G. Strategy of prevention: lessons from cardiovascular disease. Br Med J (Clin Res Ed) 1981;282:1847-51.

29. Geller AL. Smart growth: a prescription for livable cities. Am J Public Health 2003;93:1410-5.

30. Marsh DR, Schroeder DG, Dearden KA, et al. The power of positive deviance. BMJ 2004:329:1177-9.

31. Mair JS, Pierce MW, Teret SP. The city planner's guide to the obesity epidemic: zoning and fast food. The Centers for Law and the Public's Health: a Collaborative at Johns Hopkins and Georgetown Universities; 2005. Available: www.publichealthlaw.net/Zoning \%20City\%20Planners\%20Guide.pdf (accessed 2011 Jan. 27).

32. Zenk SN, Powell LM. US secondary schools and food outlets. Health Place 2008;14:336-46.

33. Finkelstein E, French S, Variyam JN, et al. Pros and cons of proposed interventions to promote healthy eating. Am J Prev Med 2004;27(Suppl):163-71.

34. Bill 90, Healthy Decisions for Healthy Eating Act. 2d Sess., 39th Leg. Ont., 2010. Available: www.ontla.on.ca/web/bills/bills_detail .do?locale $=$ en $\&$ Intranet $=\& B i l l I D=2385$ (accessed 2011 Apr. 11) .

35. Lobstein T, Dibb S. Evidence of a possible link between obesogenic food advertising and child overweight. Obes Rev 2005;6: 203-8.

36. Witkos M, Uttaburanont M, Lang CD, et al. Costs of and reasons for obesity. J Cardiometab Syndr 2008;3:173-6.

37. Healthy foods and beverages in elementary school vending machines. Toronto (ON): Ontario Ministry of Education; 2004 Available: www.edu.gov.on.ca/extra/eng/ppm/135.html (accessed 2011 Feb. 4).

Affiliations: From the Divisions of Cardiology and Clinical Epidemiology (Eisenberg, Atallah, Grandi, Windle), Jewish General Hospital, Montréal, Que.; the Department of Epidemiology, Biostatistics and Occupational Health (Eisenberg), McGill University, Montréal, Que.; and the Department of Human Nutrition and Metabolism (Berry), Braun School of Public Health, Hebrew University-Hadassah Medical School, Jerusalem, Israel

Contributors: All of the authors contributed equally to the writing and revising of the manuscript and approved the final version submitted for publication.

Funding: Mark Eisenberg is a National Researcher of the Fonds de la recherche en santé du Québec. 